\title{
First International Workshop on "Prognostic and Therapeutic Applications of Rkip in Cancer"
}

\author{
Held in Los Angeles, California, March 19-20, 2010
}

The first International Workshop on "Prognostic and Therapeutic Applications of RKIP in Cancer" was held at the University of California at Los Angeles, March 19-20, 2010. This workshop was focused on the current status of the various functions assigned to RKIP and its pivotal role in the regulation of cancer cells' survival and response to therapies. The workshop was attended by national and international experts. The topics presented included the role of RKIP in the regulation of cell survival, cell proliferation, cell response to growth factors, metastasis, and sensitivity to chemotherapy and immunotherapy, as well as its prognostic significance and its role as a new target for therapeutic intervention. Issue 1 of volume 2 is the first in a two-part series of publications of the workshop proceedings. This volume is the first to publish manuscripts and reviews on RKIP and serves as an important reference for scientists, clinicians, and students.

\section{Guest Editors}

\section{Benjamin Bonavida}

Ph.D. Professor Department of Microbiology, Immunology, \& Molecular Genetics David Geffen School of Medicine

University of California

Los Angeles, California

\section{Fahd Al-Mulla}

Associate Professor Head of Molecular Pathology

Kuwait University

\section{Kam C. Yeung}

Associate Professor

Department of Biochemistry \& Cancer Biology

University of Toledo, College of Medicine

Toledo, Ohio 


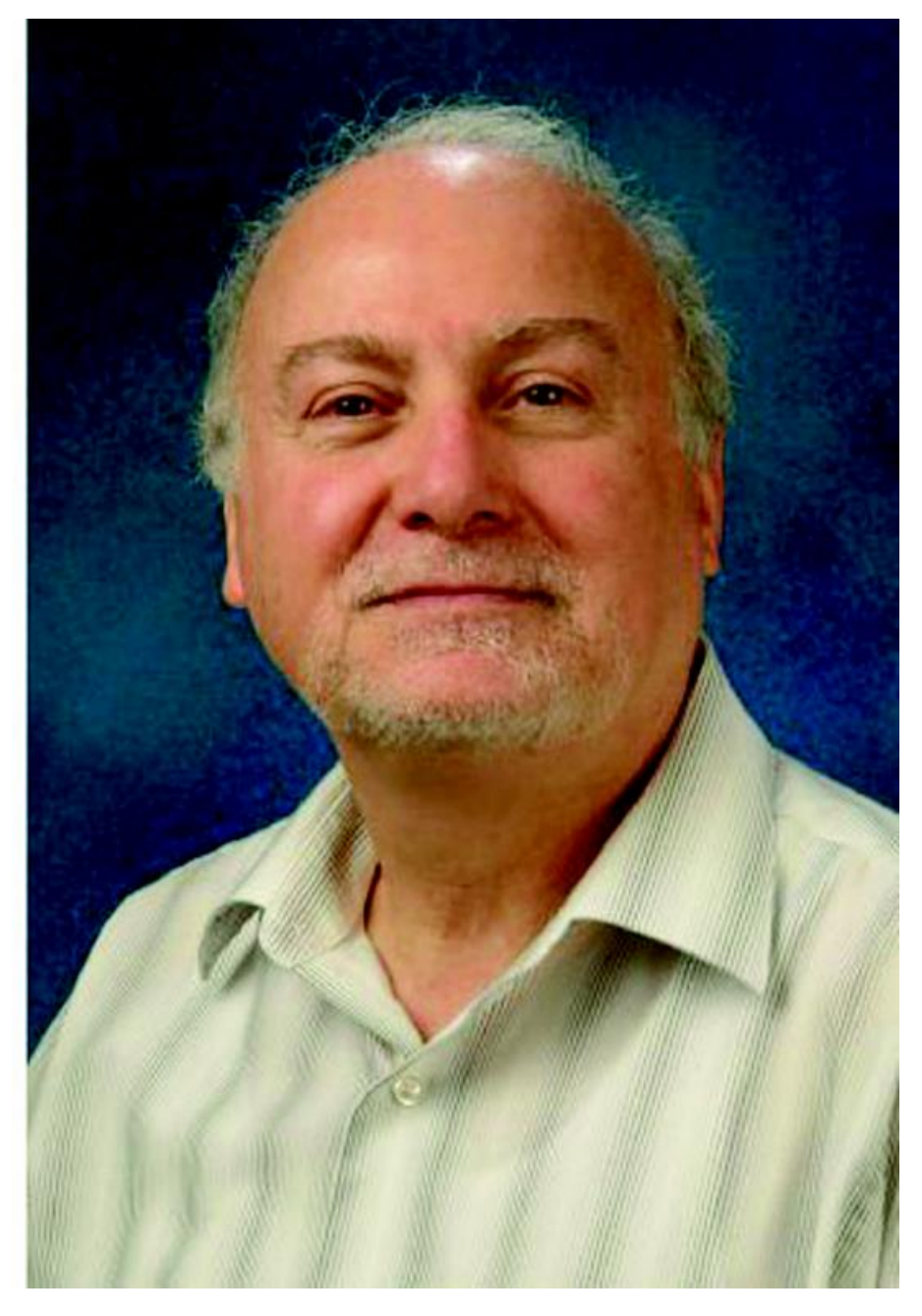

\section{Guest Editor \\ Benjamin Bonavida, Ph.D.}

Dr. Bonavida's research interests have included immunochemistry, host-immune responses, and during the last decade, studies on the immunobiology of cancer. His studies included the biochemical, molecular, and genetic underlying mechanisms of the development of resistance and metastasis in tumors. In addition, his studies investigated the molecular mechanism of Rituximab-mediated cell signaling and sensitization of tumor cells to apoptotic stimuli. At UCLA, he has trained numerous fellows and Ph.D. students. He has also been invited to several international conferences as a speaker and/or chair. Dr. Bonavida is a member of several scientific associations and is also on the editorial boards of various scientific journals. He has initiated the Workshop series and is the coeditor of Forum on Immunopathological Diseases and Therapeutics. He co-organized the RKIP workshop at UCLA, March 19-20, 2010. 


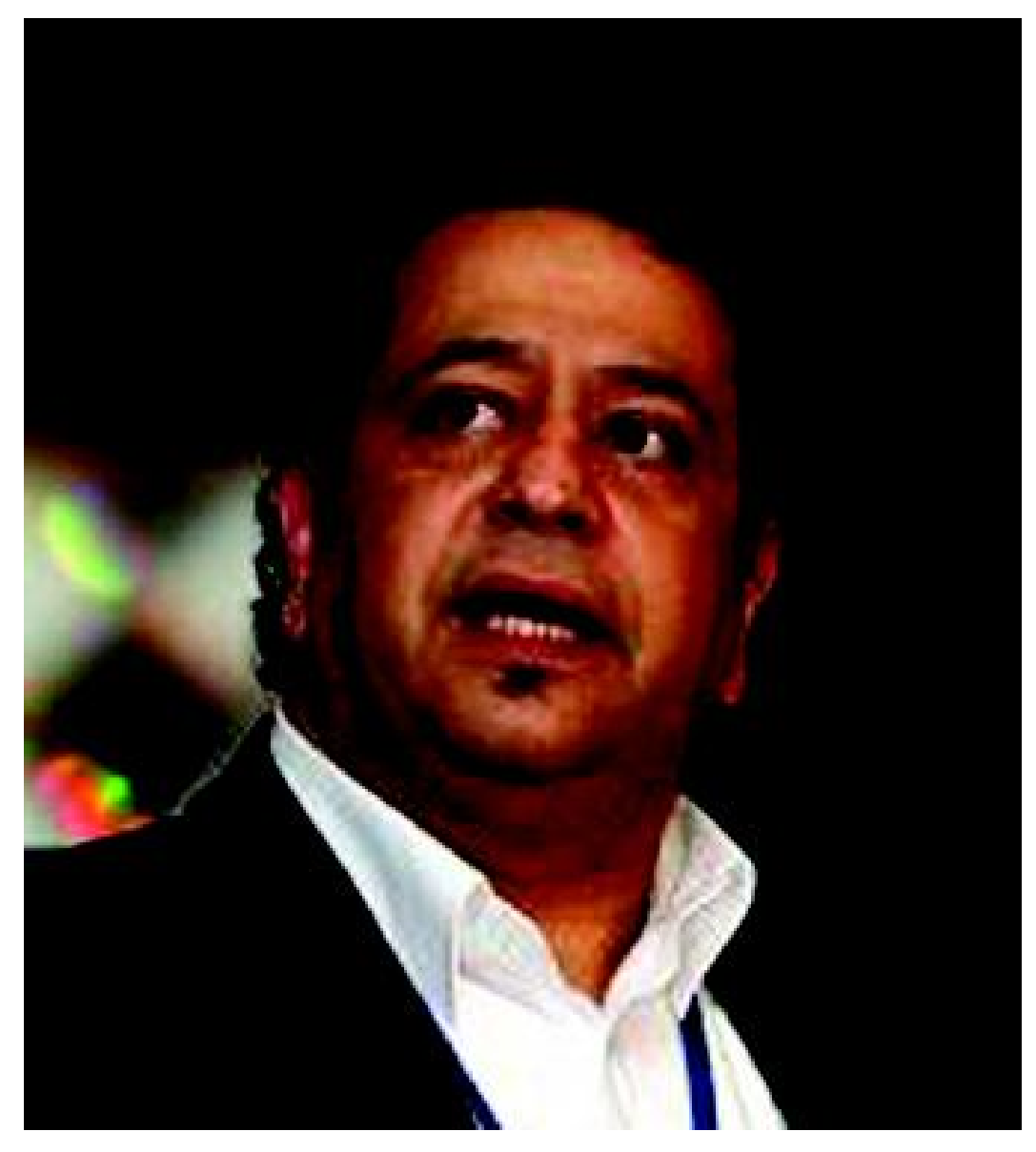

\section{Guest Editor \\ FAHD Al-Mulla}

Fahd Al-Mulla is the director of the Research Core Facility in Kuwait University Health Sciences Center. He heads a Molecular Pathology Unit, which aims at delivering state-ofthe-art diagnostic, targeted, or tailored therapy and research facilities. Currently, as head of Molecular Pathology, he is focused on the identification of novel metastasis suppressor genes in colorectal cancer and spearheads a collaborative effort to promote public awareness regarding the importance of scientific research outputs in resolving society's problems and in expediting the development process in the Arab world especially in the field of the Arab genome. Dr. Al-Mulla received his medical doctorate and Ph.D. from Glasgow University. 


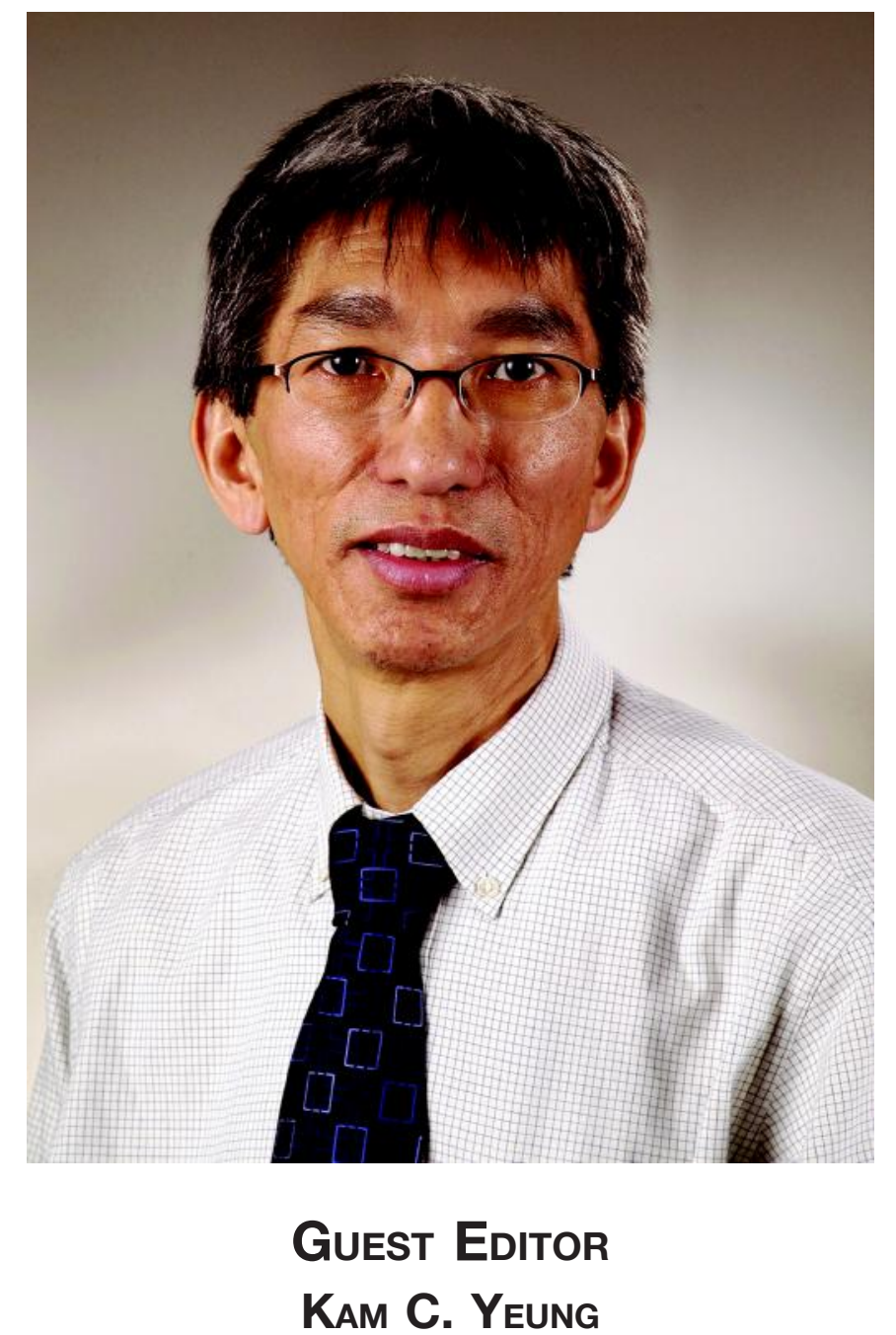

Kam Yeung received his Ph.D. from the University of South Alabama studying the molecular pathology of viral infection. His subsequent postdoctoral training was in the areas of molecular virology and transcription regulation of gene expression. The major focus of his current research program is to understand the molecular basis of cell signaling in normal and different pathological conditions at both the cellular and whole organismal levels. 